\title{
CFD and experimental studies on a circulating fluidised bed reactor for biomass gasification
}

\author{
Xi Yu ${ }^{1}$, Paula H. Blanco ${ }^{*}, 1$, Yassir Makkawi ${ }^{2}$, Anthony V. Bridgwater ${ }^{1}$ \\ 1. European Bioenergy Research Institute (EBRI), School of Engineering and Applied Science, Aston \\ University, Birmingham B4 7ET, UK \\ 2. Department of Chemical Engineering, American University of Sharjah, P.O. Box 26666, Sharjah, \\ United Arab Emirates \\ *Corresponding Author: Paula H. Blanco p.blanco-sanchez@aston.ac.uk
}

\begin{abstract}
Biomass gasification has been extensively studied in different thermochemical systems, as has the potential to produce fuel gas for chemicals, fuel and electricity applications. Circulating fluidised bed systems (CFB) are of particular interest due to the high reaction rates and thermal efficiency. The study of varying particle properties and gas velocities during the solids recirculation in a CFB system has been proved to greatly influence the overall biomass gasification process. A comparison between experimental and modelling gas-solid interactions can represent a comprehensive and analytical approach for further understanding and scaling up this reaction system. However, running several experiments is expensive and time-consuming. In this work, a reliable and accurate computational fluid dynamics (CFD) framework has been developed to evaluate the hydrodynamics performance of a CFB gasifier. The multiphase CFD model was validated using a pilot-scale CFB gasifier and silica sand. The CFD and experimental data showed good agreement for the solid recirculation tests, for example when comparing predicted and measured the spatial distribution of pressure up the gasifier's riser. It is the first time that the spatial distribution of solids around a CFB system has been numerically predicted, which can provide guidance to evaluate the hydrodynamics performance of CFB.
\end{abstract}

Keywords: gas-solid interactions, hydrodynamics, circulating fluidised bed, particle properties, CFD, heat transfer 


\section{Introduction}

Biomass gasification is an attractive technology that converts solid fuels such as biomass into a fuel gas with low or medium heating values. Depending on the gas characteristics, this can be used in further processes for the production of chemicals, fuel and electricity. CFB systems have been commercially used for biomass gasification due to their technical and operational advantages including high reaction rates, thermal efficiency, potential scalability, and higher char circulation rate which improves the overall gasification efficiency. Overall, CFB systems are preferred for large-scale applications although they can be also competitive for medium scale [1-3].

Figure 1 demonstrates a typical process flow diagram of biomass gasification for electricity. Hot air is blown upward through a bed of solid particles (biomass, sand and catalyst), keeping them in a state of entrainment and recirculation through the CFB system. The solid biomass fuel is converted into a combustible fuel gas through a series of thermo-chemical reactions. The resulting raw fuel gas, which is composed by syngas, fine particle and tar vapours; flows through the first heat exchanger, where cold air is heated up before entering gasifier. Raw fuel gas needs to be cleaned to eliminate contaminants containing particulate matter, alkali compounds, nitrogen compounds, sulphur, chlorine and tar. This cleaning stage will allow to meet environmental emission standards, as well as to protect downstream units, such as the power generator for electricity [4]. Clean-up processing consists of bag filter and wet scrubber to remove fine particles and tar from raw fuel gas. Two more heat exchangers are utilised to recover heat from hot fuel gas. The final clean syngas produces electricity by a power generator or a CHP (combined heat and power) system.

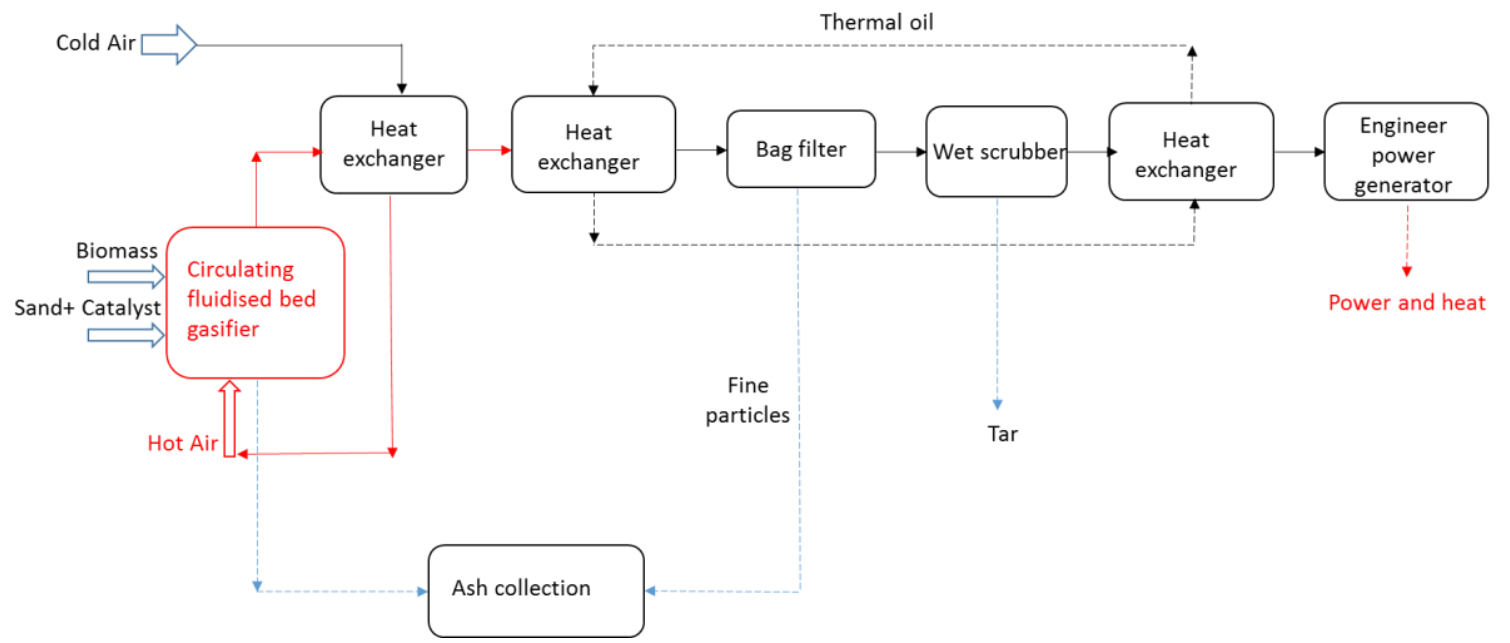

Figure 1. Process flow diagram of biomass gasification for electricity

Major constraints to scale up and further use of CFBs include the unknown effects of varying operational and design parameters during biomass gasification. Several experimental studies have reported syngas quality for small and medium scale circulating fluidised bed gasifiers using different 
biomass types [5-9]. Also previous modelling reports have addressed the effects of varying operational and design parameters, however there is a constant lack of an integrated thermochemical scheme that involves all the parallel and exothermic gasification reactions.

According to the authors' knowledge, a comprehensive CFD model including a thermochemical scheme has not been yet developed for CFB gasifiers, which derives both the hydrodynamics as well as products characteristics. Therefore one of the main objectives of the present work is to develop and validate a comprehensive CFD model, able to simulate experimental system but also able to predict diverse scenarios by modifying operational parameters or structural changes within the reactor itself. In the literature it has been reported the influence of the particle size over the fluidisation performance in a gas-solid flow system, but also the particle distribution inside a CFB gasifier, influences the overall gasification process [10]. The present work aims to develop a thorough analysis of the pressure and solid particles distribution inside the riser, cyclones, and downer of a CFB system using both experimental and modelling tools. This will allow to understand the influence of the air velocity and solid particle size in the hydrodynamics of the overall system.

\section{Experimental}

The solid recirculation experiments were carried out in a pilot-scale circulating fluidised bed (CFB), using silica sand as the bed material, and air as the fluidising agent. More details about the reaction system, materials used as well as specific procedures can be found in the following sections.

\subsection{Materials}

The solid recirculation tests were conducted using $3 \mathrm{~kg}$ of silica sand as bed material $\left(96.2 \mathrm{wt} . \% \mathrm{SiO}_{2}\right.$, Specialist Aggregates Ltd., UK). Two Geldart-B particles with different sizes of $0.3 \mathrm{~mm}$ and $0.6 \mathrm{~mm}$, were used in order to identify the influence of the particle size over the solids recirculation.

\subsection{CFB system}

A $12 \mathrm{~kg} / \mathrm{h}$ circulating fluidised bed rig (CFB) was used to study the solid recirculation at room temperature; the schematic diagram of the experimental system is shown in Figure 2. 

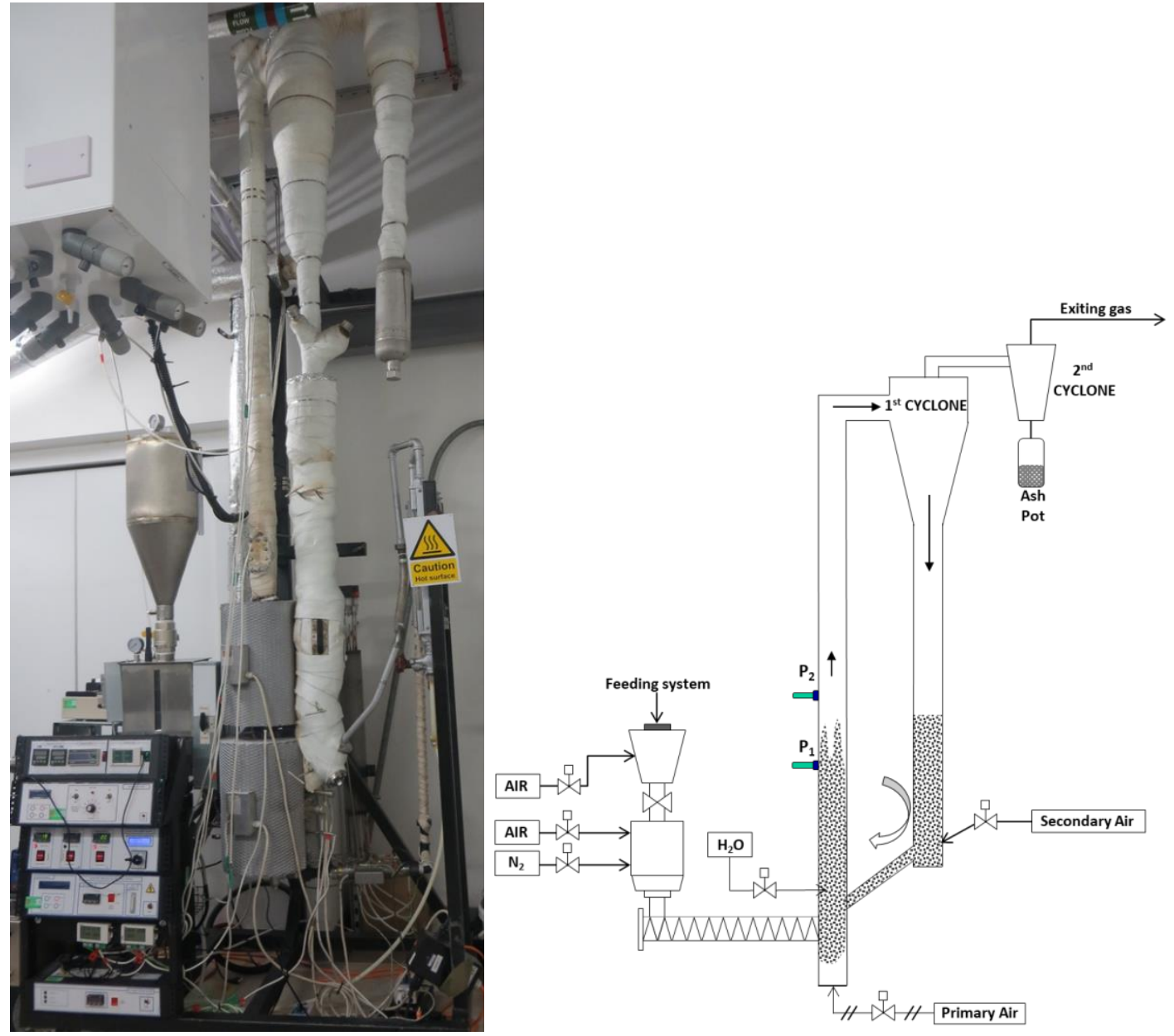

Figure 2. Diagram of the Circulating Fluidised Bed (CFB) experimental system

The solid recirculation tests were carried out using air at ambient conditions. A low air flow rate of about $60 \mathrm{ml} / \mathrm{min}$, was introduced into the feeding system in order to avoid any solids going inside the hopper by means of the solids recirculation taking place inside the riser. Air was used as the main carrying medium to promote solid circulation inside the gasifier; the primary air supply was at the bottom of the reactor and the flowrate was controlled using a flowmeter. A secondary air supply, also controlled by means of a flowmeter, was used to aid the transfer of solids from the downer to the riser (Figure 2), this flowrate was about $10 \%$ of the main air supply.

The body of the reactor was made of stainless steel, with a total height of $310 \mathrm{~cm}$ and an internal diameter of $4 \mathrm{~cm}$. Two pressure gauges were located in the riser at heights of $40 \mathrm{~cm}$ and $70 \mathrm{~cm}$, shown as $\mathrm{P}_{1}$ and $\mathrm{P}_{2}$ in Figure 2, respectively. The pressure gauges were connected via a USB to a computer and HOBOware software, which allowed the pressure to be constantly monitored during the experiment. A primary cyclone was located at the top of the riser to promote separation between gas and solids. The solids were recirculated and transferred into the downer. A secondary cyclone allowed the collection of fine solids (if any) by using an ash pot; the exiting air was passed through an exhaust 
line, then through a flowmeter to double check the air flow rate, and finally the air was released to the atmosphere.

Initial experiments to study the solids behaviour of the bed material during recirculation, and varying the air flow rates were carried out. The experimental parameters used are shown in Table 1.

Table 1. Solids recirculation: experimental parameters using air at $25^{\circ} \mathrm{C}$

\section{Test No.}

Primary air flow (L/min)

Secondary air flow (L/min)

Total air flow rate $(\mathrm{L} / \mathrm{min})$

Gas velocity $(\mathrm{m} / \mathrm{s})$

Sand particle size $(\mathrm{mm})$

Cold recirculation tests

\begin{tabular}{cccccc}
\hline 1 & 2 & 3 & 4 & 5 & 6 \\
80 & 140 & 205 & 120 & 205 & 320 \\
20 & 40 & 40 & 30 & 40 & 30 \\
100 & 180 & 245 & 150 & 245 & 350 \\
1.33 & 2.39 & 3.25 & 1.99 & 3.25 & 4.64 \\
0.3 & 0.3 & 0.3 & 0.6 & 0.6 & 0.6 \\
\hline
\end{tabular}

The gas velocity shown in Table 1 corresponds to the air velocity up the riser; and it was calculated considering the total air flowrate and the riser's geometry as follows:

$$
U_{G}=Q_{G} / A_{R}
$$

Where $Q_{G}$ is the air flow rate in $\mathrm{m}^{3} / \mathrm{sec}$, and $A_{R}$ is the total inlet cross-section area of the riser in $\mathrm{m}^{2}$. In this study, $A_{R}$ is $0.001257 \mathrm{~m}^{2}$.

\section{CFD model}

A 3D Eulerian-Eulerian multiphase model based on a CFD framework was developed in order to study the hydrodynamic behaviour of sand-air flow in a circulating fluidised bed (CFB) system. The gasparticle hydrodynamics were modelled by coupling k-epsilon turbulent model and kinetics theory of granular flow (KTGF). The CFD model developed was solved using the commercial software ANSYS FLUENT (Ver. 15). The developed CFD model can be found in our previous studies [11, 12].

The main model equations for non-reacting isothermal gas-solid flow are given by the following continuity and momentum equations:

\begin{tabular}{l}
\hline Continuity equations \\
$\frac{\partial\left(\alpha_{g} \rho_{g}\right)}{\partial t}+\nabla\left(\alpha_{g} \rho_{g} \vec{u}_{g}\right)=0$ \\
$\frac{\partial\left(\alpha_{s} \rho_{s}\right)}{\partial t}+\nabla\left(\alpha_{s} \rho_{s} \vec{u}_{s}\right)=0$ \\
$\alpha_{s}+\alpha_{g}=1$
\end{tabular}

Momentum equations 


$\frac{\partial\left(\alpha_{g} \rho_{g} \vec{u}_{g}\right)}{\partial t}+\nabla\left(\alpha_{g} \rho_{g} \vec{u}_{g} \vec{u}_{g}\right)=-\alpha_{g} \nabla P+\nabla \overline{\bar{\tau}}_{g}-\sum_{i=1}^{3} \beta_{g s_{i}}\left(\vec{u}_{g}-\vec{u}_{s_{i}}\right)+\alpha_{g} \rho_{g} g$
$\frac{\partial\left(\alpha_{s} \rho_{s} \vec{u}_{s}\right)}{\partial t}+\nabla\left(\alpha_{s} \rho_{s} \vec{u}_{s} \vec{u}_{s}\right)=-\alpha_{s} \nabla P-\nabla P_{s}+\nabla \overline{\bar{\tau}}_{s}+\beta_{g s}\left(\vec{u}_{g}-\vec{u}_{s}\right)+\alpha_{s_{i}} \rho_{s} g$
Where...
$\overline{\bar{\tau}}_{k}=\left(\lambda_{k}-\frac{2}{3} \mu_{k}\right)\left(\nabla \cdot \vec{u}_{k}\right) \overline{\bar{I}}+2 \mu_{k} \overline{\bar{S}}_{k}$
$\overline{\bar{S}}_{k}=\frac{1}{2}\left(\nabla \vec{u}_{k}+\left(\nabla \vec{u}_{k}\right)^{T}\right)$
$k$, represents solid or gas phase

To obtain the granular temperature, the FLUENT code was set to use a partial differential equation (Pseudo Energy Equation) as follows [13]:

$$
\frac{3}{2}\left[\frac{\partial\left(\alpha_{s} \rho_{s} \Theta_{s}\right)}{\partial t}+\nabla\left(\alpha_{s} \rho_{s} \Theta_{s}\right) \vec{u}_{s}\right]=\left(-P_{s} \overline{\bar{I}}+\overline{\bar{\tau}}_{s}\right): \nabla \vec{u}_{s}+\nabla\left(\kappa_{T} \nabla \Theta_{s}\right)-\gamma_{T}+\phi_{k s}
$$

The various closure and constitutive relations used in the model are given in Table 2. In order to take into consideration the solid-solid frictional stresses in the dense regions of the reactor, the friction equation proposed by Schaeffer [14] was used. Due to the high turbulence of the flow, the standard Kepsilon turbulence and energy dissipation equations proposed by Launder and Spalding [15] were also incorporated in the model and these are given as follows:

\section{Turbulence momentum equations}

$\frac{\partial\left(\alpha_{g} \rho_{g} k_{g}\right)}{\partial t}+\nabla\left(\alpha_{g} \rho_{g} \vec{u}_{g} k_{g}\right)=\alpha_{g} G_{k, g}+\nabla\left(\alpha_{g} \frac{\mu_{t, g}}{\sigma_{k}} k_{g}\right)-\alpha_{g} \rho_{g} \varepsilon_{g}+\alpha_{g} \rho_{g} \Pi_{k, g}$

\section{Turbulent kinetic energy dissipation equation}

$\frac{\partial\left(\alpha_{g} \rho_{g} \varepsilon_{g}\right)}{\partial t}+\nabla\left(\alpha_{g} \rho_{g} \vec{u}_{g} \varepsilon_{g}\right)=\nabla\left(\alpha_{g} \frac{\mu_{t, g}}{\sigma_{\varepsilon}} \varepsilon_{g}\right)+\alpha_{g} \frac{\varepsilon_{g}}{k_{g}}\left(C_{1 \varepsilon} G_{k, g}-C_{2 \varepsilon} \rho_{g} \varepsilon_{g}\right)+\alpha_{g} \rho_{g} \Pi \Pi_{\varepsilon, g}$

Where...

$G_{k, g}=\mu_{t, g}\left(\nabla \vec{u}_{g}+\left(\nabla \vec{u}_{g}\right)^{T}\right): \nabla \vec{u}_{g}$

$C_{\mu}=0.09, C_{1 \varepsilon}=1.44, C_{2 \varepsilon}=1.92, \sigma_{k}=1, \sigma_{\varepsilon}=1.3$

Table 2. Constitutive relations for the gas-solid flow

Solids pressure

$$
P_{S}=\alpha_{s} \rho_{\mathrm{s}} \Theta_{\mathrm{s}}+2 g_{0, \mathrm{ss}} \rho_{\mathrm{s}} \alpha_{s}^{2} \Theta_{S}\left(1+e_{s S}\right) \quad(T 1-1)
$$

Solids shear viscosity 
$\mu_{\mathrm{s}}=\mu_{\mathrm{s}, \mathrm{col}}+\mu_{\mathrm{s}, \text { kin }}+\mu_{\mathrm{s}, f r} \quad(T 1-2)$

Collisional viscosity [16]

$\mu_{s, c o l}=\frac{4}{5} \alpha_{s} \rho_{\mathrm{s}} d_{\mathrm{s}} g_{0, \mathrm{ss}}\left(e_{s s}+1\right)\left(\frac{\Theta_{s}}{\pi}\right)^{1 / 2}(T 1-3)$

Kinetic viscosity [17]

$\mu_{s, k i n}=\frac{\alpha_{\mathrm{s}} \rho_{\mathrm{s}} d_{s} \sqrt{\theta_{\mathrm{s}} \pi}}{6\left(3-e_{\mathrm{ss}}\right)}\left[1+\frac{2}{5}\left(e_{\mathrm{ss}}+1\right)\left(3 e_{\mathrm{ss}}-1\right) \alpha_{\mathrm{s}} g_{0, \mathrm{ss}}\right] \quad(T 1-4)$

Friction viscosity [14]

$\mu_{s, f r}=\frac{P_{s} \sin \phi}{2 \sqrt{I_{2 D}}} \quad(T 1-5)$

Bulk viscosity [18]

$\lambda_{s}=\frac{4}{3} \alpha_{\mathrm{s}} \rho_{\mathrm{s}} d_{\mathrm{s}} g_{0, \mathrm{ss}}\left(e_{\mathrm{ss}}+1\right)\left(\frac{\Theta_{\mathrm{s}}}{\pi}\right)^{1 / 2}(T 1-6)$

Radial distribution function

$g_{0, s s}=\left(1-\left(\frac{\alpha_{s}}{\alpha_{s, \max }}\right)^{1 / 3}\right)^{-1}(T 1-7)$

$\mu_{g}=\mu_{l, g}+\mu_{t, g}, \quad \mu_{t, g}=C_{\mu} \alpha_{g} \rho_{g} \frac{k_{g}^{2}}{\varepsilon_{g}} \quad(T 1-8)$

Gas-solid drag coefficient [19]

$\beta_{g s}=\frac{3 \rho_{g} \alpha_{\mathrm{s}} \alpha_{g}}{4 u_{r, s}^{2} d_{\mathrm{s}}} C_{D}\left(\frac{R e_{\mathrm{s}}}{v_{r, \mathrm{~s}}}\right)\left|\vec{u}_{g}-\vec{u}_{\mathrm{s}}\right| \quad(T 1-9)$

$v_{r, s}=0.5\left(A-0.06 R e_{\mathrm{s}}+\sqrt{\left(0.06 R e_{\mathrm{s}}\right)^{2}+0.12 R e_{\mathrm{s}}(2 B-A)+A^{2}}\right) \quad(T 1-10)$

$A=\alpha_{g}^{4.14}, \quad\left\{\begin{array}{c}B=0.8 \alpha_{g}^{1.28}\left(\alpha_{g} \leq 0.85\right) \\ B=\alpha_{g}^{2.65}\left(\alpha_{g}>0.85\right)\end{array}\right.$

$C_{D}=\left(0.63+\frac{4.8}{\sqrt{R e_{s} / v_{r, \mathrm{~s}}}}\right)^{2} \quad(T 1-11)$

$R e_{\mathrm{s}}=\frac{d_{\mathrm{s}} \rho_{g}\left|\vec{u}_{g}-\vec{u}_{s}\right|}{\mu_{g}} \quad(T 1-12)$

Diffusion coefficient of granular energy [16]

$\kappa_{\Theta_{\mathrm{s}}}=\frac{150 \rho_{\mathrm{s}} d_{\mathrm{s}}\left(\pi \Theta_{\mathrm{s}}\right)^{\frac{1}{2}}}{384\left(e_{\mathrm{ss}}+1\right) g_{0, \mathrm{ss}}}\left[1+\frac{6}{5} \alpha_{\mathrm{s}} g_{0, \mathrm{ss}}\left(e_{\mathrm{ss}}+1\right)\right]^{2}+2 \alpha_{s}^{2} \rho_{s} d_{\mathrm{s}} g_{0, \mathrm{ss}}\left(e_{\mathrm{ss}}+1\right)\left(\frac{\Theta_{\mathrm{s}}}{\pi}\right)^{\frac{1}{2}}$

$(T 1-13)$

Collisional energy dissipation [18],

$\gamma_{\Theta_{s}}=\frac{12\left(1-e_{\mathrm{ss}}^{2}\right) g_{0, \mathrm{ss}}}{d_{\mathrm{s}} \pi^{1 / 2}} \alpha_{\mathrm{s}}^{2} \rho_{s} \Theta_{\mathrm{s}}^{3 / 2} \quad(T 1-14)$ 


\subsubsection{Computational domain and operating conditions}

The computational domain and geometry of the pilot scale CFB used in this study consists of a riser (4 $\mathrm{cm}$ diameter and $310 \mathrm{~cm}$ height); the top of the riser is connected to a primary cyclone, which in turn is connected to a downer. The top of the primary cyclone is connected to a secondary cyclone to collect fine particles before the gas leaves the reactor. This defined geometry for CFD, is in agreement to that of the reactor used to validate the model. The general diagram created in CFD, the distribution of the residence time, and a graph showing the mean gas residence time, are shown in the Figure 3 below.

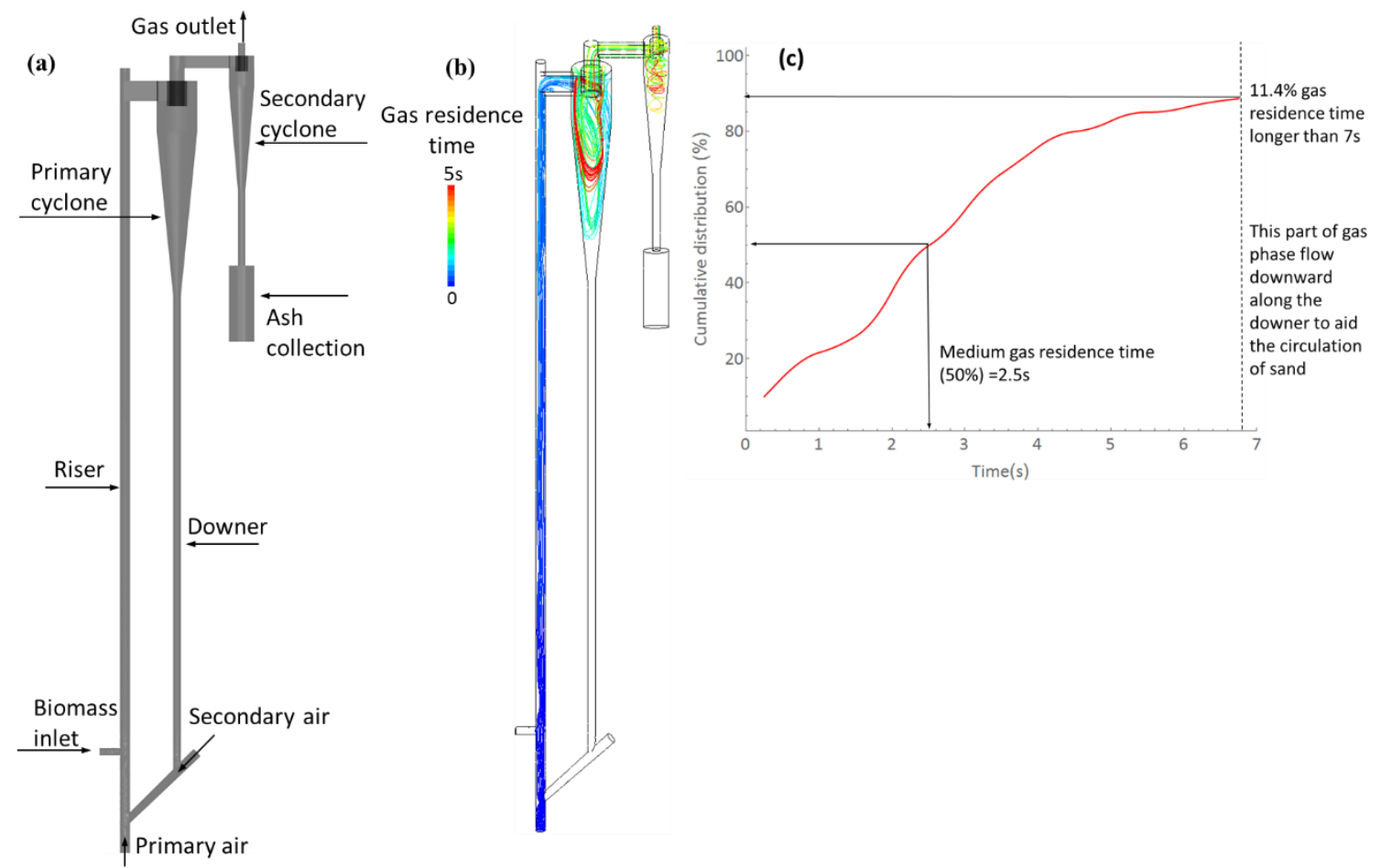

Figure 3. (a) CFB computational domain and geometry (b) Path line of tracked particles along the velocity field of gas at steady state condition. (c) The fitted cumulative distribution of gas residence time based on path line analysis.

From Figure 3, the flow in the CFB reactor includes solid materials (sand) and a fluid in gas phase (air at room temperature). The computational domain of the CFB system consists of 114,100 computational cells for the mesh. Further details on the reactor operating conditions and the physical properties of the material used in the model are given in Table 3. 
Table 3. Gas and solid phase boundary/operating conditions used in the CFD model

\begin{tabular}{l|c|c}
\hline Boundary/operating condition & Experiment & Model \\
\hline Gas flow rate, $\dot{V}_{g}[\mathrm{~L} / \mathrm{min}]$ & $100-350$ & $100-350$ \\
Gas density, $\rho_{g}\left[\mathrm{~kg} / \mathrm{m}^{3}\right]$ & 1.2 & $1.2^{*}$ \\
Gas dynamic viscosity $[\mathrm{kg} /(\mathrm{m} . \mathrm{s})]$ & $1.8 \times 10^{-5}$ & $1.8 \times 10^{-5 *}$ \\
Gas outlet pressure, $P_{g o}[\mathrm{Pag}]$ & 0 (ambient) & $0^{*}(\mathrm{ambient})$ \\
Particle density, $\rho_{P}\left[\mathrm{~kg} / \mathrm{m}^{3}\right]$ & 2650 & $2650^{*}$ \\
Solid packing load, $M[\mathrm{~kg}]$ & 3.00 & 3.00 \\
Mean particle size, $\bar{d}_{s}[\mathrm{~mm}]$ & $0.3,0.6$ & $0.3,0.6$ \\
\hline "Default simulation conditions, unless otherwise specified
\end{tabular}

From Table 3 the gas residence time within the CFB from the primary air inlet to the gas exit is addressed by reporting particle density and solid packing load, this method is also referred to in the literature as particle tracking or trajectory calculation [12]. A numerical example is shown in Figure $3 \mathrm{~b}$ above, where 36 massless particles were released from the primary air inlet. Owing to the statistical behaviour of particle tracking, post-processing simulation of particle tracking were run ten times and total of 360 massless particles were released at different points from the primary air inlet (where residence time was equal to zero). The predicted cumulative distribution of gas residence time within the downer reactor is shown in Figure 3c above, the residence time of $2.2 \mathrm{~s}$ at $50 \%$ was used to represent the mean gas residence time.

\subsubsection{Computation procedure and boundary conditions}

The equations for governing the CFD model were solved via the finite volume approach. First-order discretization schemes were used for the solution of the convection terms in all governing equations. The linearized governing equations were solved using block algebraic multi-grid method. The relative error between any two successive iterations was quantified through a convergence criterion of $10^{-3}$ for each scaled residual component. The phase-coupled SIMPLE (PC-SIMPLE) algorithm, which is an extension of the SIMPLE algorithm to multiphase flows, was applied for the pressure-velocity coupling.

It is difficult to precisely estimate the initial packing height of solids for a given pressure drop, by trial and error. In this work the CFB was initially packed with solids with a volume fraction of 0.45 and packing height of $2.5 \mathrm{~m}$ in the downer side. If not specified, default values in ANSYS-Fluent were used for the other parameters. In order to avoid numerical instabilities and ensure capturing the hydrodynamic feature, the solution time step for the reactive system was set to a relatively small time step of $0.0005 \mathrm{~s}$. It was shown that a time step of $0.0005 \mathrm{~s}$ is sufficient to satisfy the Courant-FriedrichsLewy (CFL) condition for accurate solution $[11,12]$. The maximum allowable number of iterations per time step was also set at 20. 
In setting the boundary conditions, the tip of the gas outlet was set at atmospheric pressure. At the walls, no-slip wall condition was specified for the gas phase and a slip velocity and granular temperature was specified for the solid phase using Johnson and Jackson boundary equations [20]. The computer used to carry out the simulation was a LENOVO ThinkStation Workstation (2.3 Ghz 16 Core processors with $32 \mathrm{~GB}$ RAM). Each case was run for around 20 seconds, in order to allow the hydrodynamics to reach steady state in operation of the CFB. As a reference, the computation time for $1 \mathrm{~s}$, equalled to a real processing time of $5 \mathrm{hr}$ and using 4 cores.

\section{Results and discussion}

The results obtained from the CFD modelling were validated through experimental tests, aimed at understanding the solid recirculation inside the reaction system. Similarly to the simulations, the influence of both the sand particle size $(0.6 \mathrm{~mm}$ and $0.3 \mathrm{~mm})$ and the air velocity were tested. 


\subsection{Flow pattern}

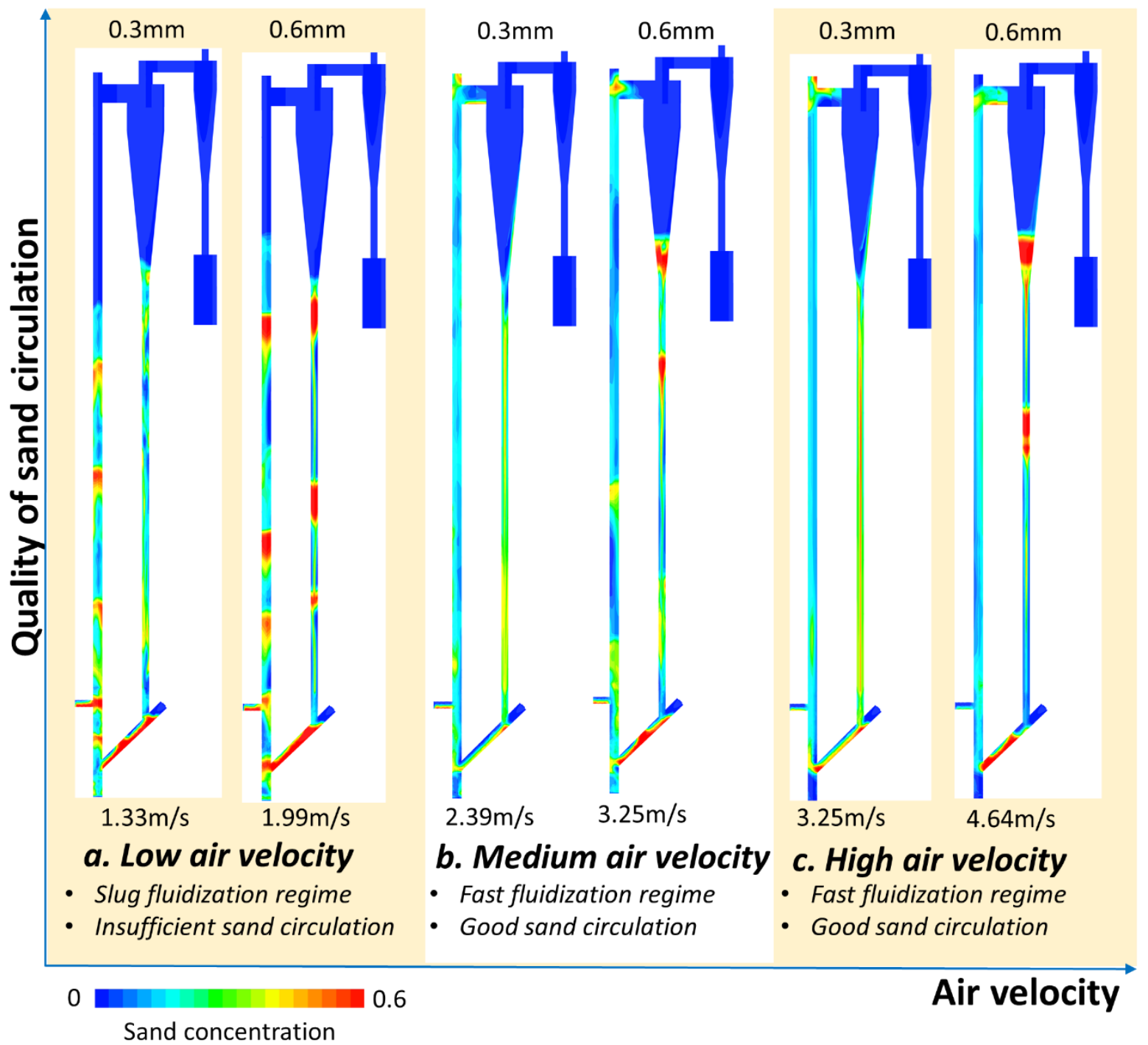

Figure 4. Contour snapshot of sand $(0.3 \mathrm{~mm}$ and $0.6 \mathrm{~mm})$ concentration (volume fraction) under different air velocity at steady condition

Figure 4 shows the influence of air velocity (from 1.33 to $4.64 \mathrm{~m} / \mathrm{s}$ ) on the flow pattern of air-sand two phase flow. When using a total air flow rate of $100 \mathrm{~L} / \mathrm{min}$, corresponding to an air velocity of $1.33 \mathrm{~m} / \mathrm{s}$ and fine sand particles of $0.3 \mathrm{~mm}$, the air velocity is not high enough to evenly drag the sand particles up the riser, therefore a bubbling fluidising profile is observed in Figure 4a. Owing to large amount of particles suspended up the riser, a dense particle bed leads to high pressure and causes part of the air to flow in the opposite direction (anticlockwise direction) up the downer side in Figure 4a. When the air velocity increases up to $2.39 \mathrm{~m} / \mathrm{s}$, the sand concentration is more evenly distributed up the riser and also in the downer, which implies the development of a fast fluidisation profile in Figure $4 \mathrm{~b}$. By further increasing the gas velocity up to $3.25 \mathrm{~m} / \mathrm{s}$, the sand starts to concentrate at the extremes of the system, particularly in the connection between the riser and the primary cyclone at the top, and in the connecting line between the bottom of the downer and the riser in Figure 4c. As the rapid and instantaneous 
separation of air and sand occurs in the primary cyclone, the sand does not accumulate and the sand concentration is diluted there. Owing to the large sand particle size $>0.3 \mathrm{~mm}$ used in this study, there is almost no sand exiting at secondary cyclone, which aims to collect fine particles such as ash.

A similar trend is observed when using coarse particles $(0.6 \mathrm{~mm})$, however the requirements for air velocity are higher due to the lower drag coefficient shown by coarse particles. Overall, the concentration distribution of sand of $0.6 \mathrm{~mm}$ is less uniform up the riser of the CFB compared to the smaller $0.3 \mathrm{~mm}$ particles.

\subsection{Pressure profiles and prediction}

During the recirculation of sand the pressure was constantly recorded by using two pressure probes located at $40 \mathrm{~cm}$ and $70 \mathrm{~cm}$ up the riser. Additionally the software HOBOware was used to transduce signals into pressure units. For each test, $3 \mathrm{~kg}$ of silica sand with two particle sizes of $0.3 \mathrm{~mm}$ and 0.6 $\mathrm{mm}$, were tested separately for continuous recirculation in a $12 \mathrm{~kg} \mathrm{~h}^{-1} \mathrm{CFB}$ reaction system (Figure 2). The recirculation of solids was maintained for about 1 hour and the variations of the pressures up the riser are shown in the Figure 5 below.

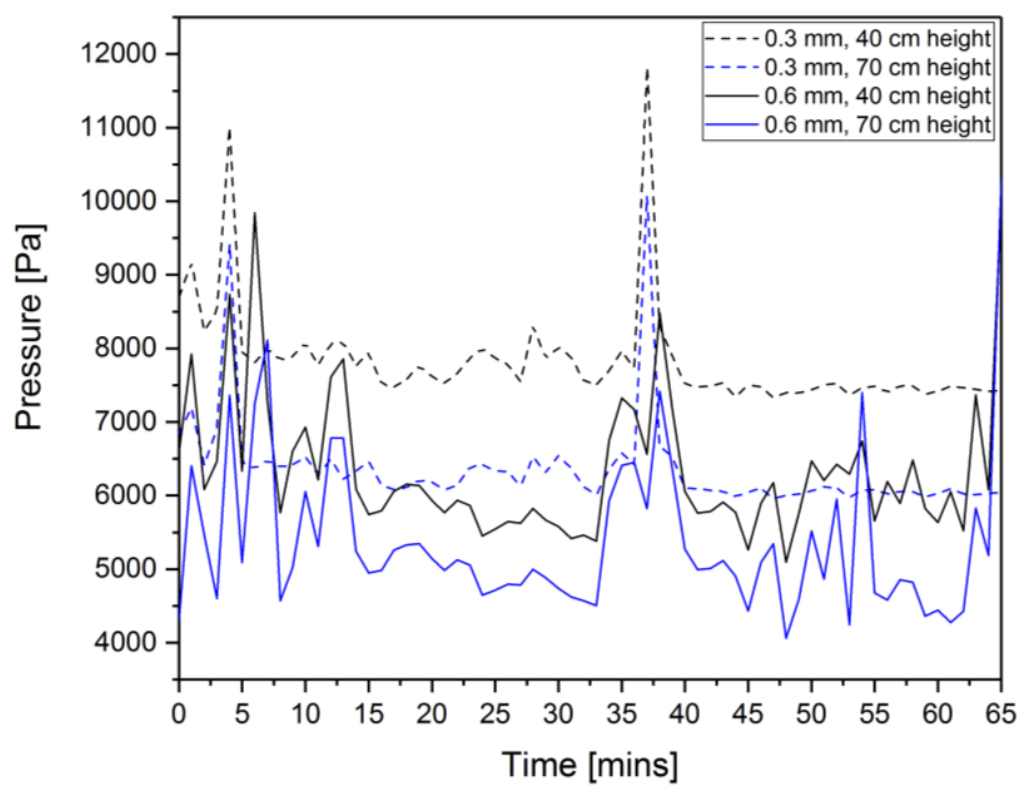

Figure 5. Variation in the pressures in a CFB reactor during recirculation of $3 \mathrm{~kg}$ of silica sand with particle sizes of $0.3 \mathrm{~mm}$ (dashed lines) and $0.6 \mathrm{~mm}$ (solid lines)

In the above Figure 5, the dashed lines represent the pressures for the small particle size of $0.3 \mathrm{~mm}$, whereas the solid lines show the pressures for the bigger particle size of $0.6 \mathrm{~mm}$. For the tests using 0.3 $\mathrm{mm}$ (dashed lines), the air flow rate was varied between 160 and $180 \mathrm{~L} \mathrm{~min}^{-1}$, with aid of a secondary air stream between 40 and $30 \mathrm{~L} \mathrm{~min}^{-1}$. This resulted in an overall flowrate of around $200 \mathrm{~L} \mathrm{~min}^{-1}$, with an average pressure around $7079 \mathrm{~Pa}$. The major peaks observed around $37 \mathrm{~min}$ (dashed lines), were due 
to adjustments in order to maintain the constant recirculation. This also demonstrates the sensitivity of the probes to changes in the air flowrates. Once the constant solids recirculation is achieved at an air velocity of $2.79 \mathrm{~m} / \mathrm{s}$, smoother patterns or variations from the pressure probes can be observed, which is desirable in order to achieve a fast fluidization regime in the system.

When using $3 \mathrm{~kg}$ of $0.6 \mathrm{~mm}$ silica sand (Figure 5, solid lines), it was observed that the air requirement for recirculation was much higher. This was related to the lower drag coefficient and higher gas velocity required to move the bigger particles and also to achieve similar pressure gradients up the riser [10]. For example $250 \mathrm{~L} \mathrm{~min}^{-1}$ from the main air, plus $40 \mathrm{~L} \mathrm{~min}^{-1}$ from the secondary air were required to achieve the recirculation of solids, thus resulting in an overall air requirement of nearly $300 \mathrm{~L} \mathrm{~min}^{-1}$ for this particle size. The higher air requirement for a bigger particle size, also reflected a reduction in the pressure down to $5916 \mathrm{~Pa}$ (Figure 5). The peaks observed around $37 \mathrm{~min}$ (solid line), were also due to adjustments in the air flow rate in order to maintain the solids recirculation. Additionally, it was observed that experimentally more manipulation of the air supply was required to achieve a constant recirculation even at room conditions. This is observed in Figure 5 as more variations in the pressure profile (solid lines).

When comparing the pressure variations for both particle sizes, it is observed that using sand with 0.3 $\mathrm{mm}$ (dashed lines) a more stable pressure profile was attained, whereas major variations were noted when using $0.6 \mathrm{~mm}$ particle size (solid lines). Also it is worth to mention that as the riser height increases, a reduction in the pressure was observed (Figure 5), and this was due to a reduction in the density of solids due to pneumatic transportation. In order to verify this trend in the pressure, two additional probes were placed at higher points up the riser, at $210 \mathrm{~cm}$ and $270 \mathrm{~cm}$ respectively. For this test, $3 \mathrm{~kg}$ of $0.6 \mathrm{~mm}$ silica sand were used and with a total air flow rate around $300 \mathrm{~L} \mathrm{~min}^{-1}$. The recorded pressures are shown in the Figure 6 below. 


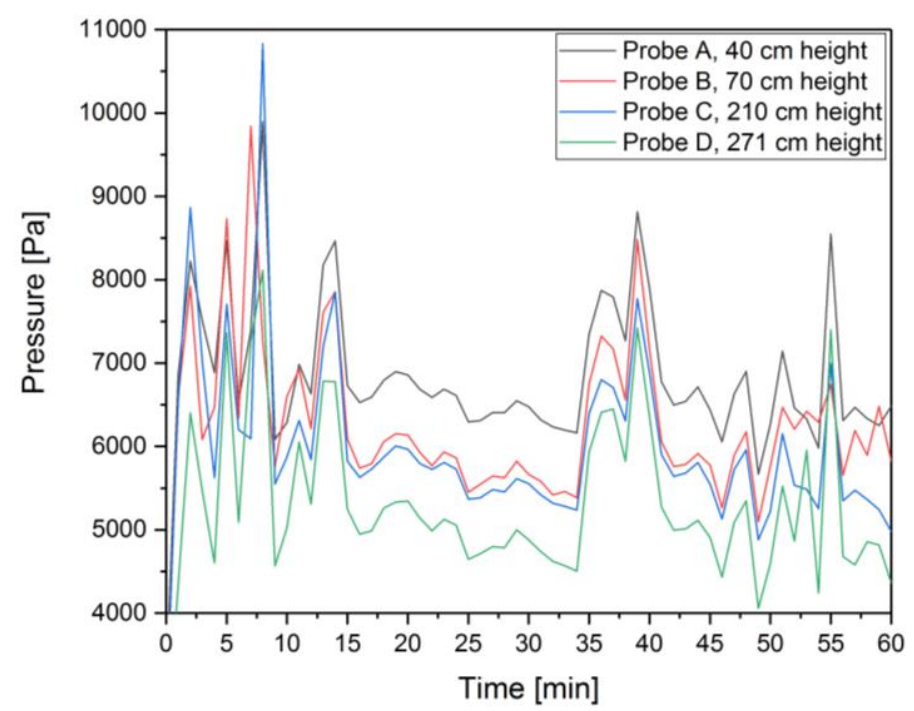

Figure 6. Variation in the pressure up the riser at different heights when recirculating $3 \mathrm{~kg}$ of $0.6 \mathrm{~mm}$ silica sand.

From Figure 6 it is observed that as the riser's height increases, the pressure is reduced due to more spaces between the solid particles at higher points. These experimental observations were compared against the CFD model developed. During simulations, the fluctuations observed in the pressure signal needed to be reduced in order to obtain a better pressure profile, but also to demonstrate the influence of air flow rate on pressure distribution under different air flow rates from $100 \mathrm{~L} \mathrm{~min}^{-1}\left(1.33 \mathrm{~m} \mathrm{~s}^{-1}\right)$ up to $245 \mathrm{~L} \mathrm{~min}^{-1}\left(3.25 \mathrm{~m} \mathrm{~s}^{-1}\right)$. Figure 7 shows the time-averaged pressure loops along axis line of the $\mathrm{CFB}$ system operated with sand of $0.3 \mathrm{~mm}$ particle size.
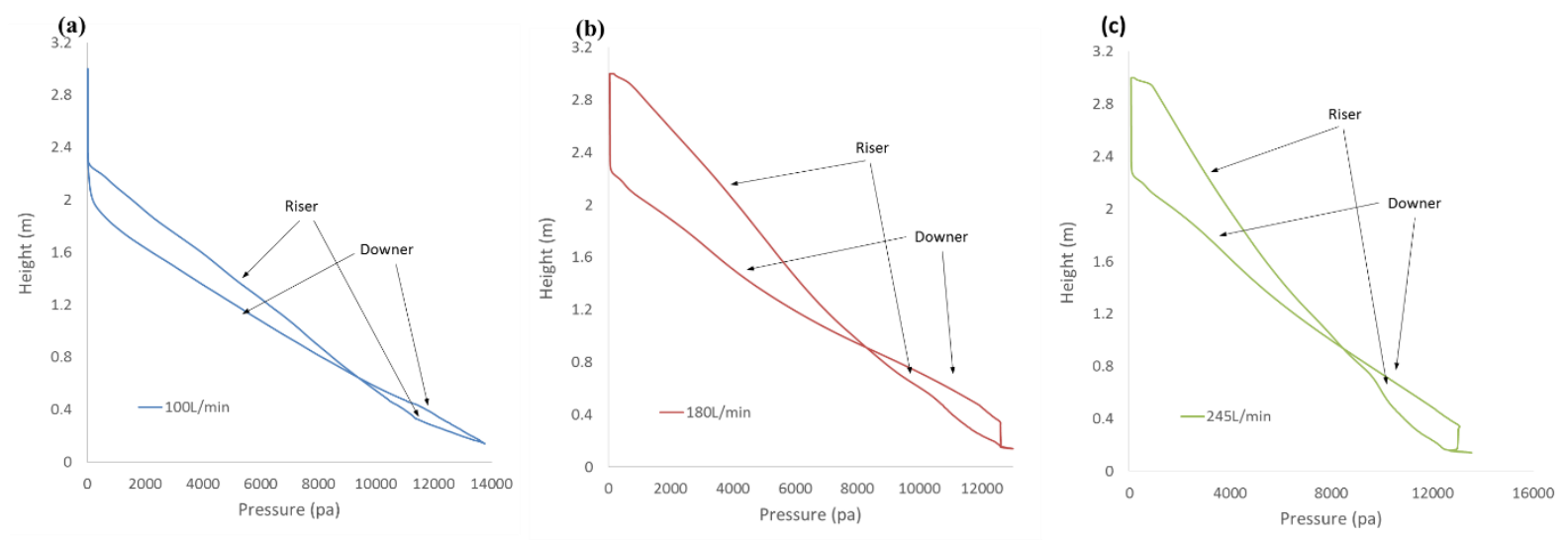

Figure 7. Time-averaged pressure loops around the CFB system operated with sand of $0.3 \mathrm{~mm}$

From Figure 7, it is observed that the static pressure of sand-air mixture decreases when it flows up the riser, and it increases once sand is separated from air in the primary cyclone and falls into the downer pipe. This behaviour was observed for all the air flow rates between 100 and $245 \mathrm{~L} \mathrm{~min}^{-1}$. It was also observed that the change of pressure was strongly related to the sand concentration. For example at a low air flow rate of $100 \mathrm{~L} \mathrm{~min}^{-1}$, the pressure difference between the riser and downer is insignificant owing to insufficient circulation of sand. An average pressure around $8500 \mathrm{~Pa}$ was obtained from the 
simulation when using $0.3 \mathrm{~mm}$ and 180 and $245 \mathrm{~L} / \mathrm{min}$, whereas from the experimental, an average pressure around $7000 \mathrm{~Pa}$ was obtained for $200 \mathrm{~L} / \mathrm{min}$ for the same system. The differences can be attributed to small variation when developing the model, however the profile obtained from the CFD follows that from the experimental results, thus validating the model in terms of hydrodynamics and solids recirculation for $0.3 \mathrm{~mm}$.

Additionally, under these conditions, the gas phase encounters a similar resistance to lift sand up within the riser and in the downer, thus promoting the development of a bubbling regime in both the downer and riser. The pressure significantly decreases down to $0 \mathrm{~Pa}$ at around $2 \mathrm{~m}$, which is the maximum height a particle bed can be suspended. From Figure 7a-c, it is observed that there is always an intersection of pressure curves between riser and downer as the air flow rate increases from $100 \mathrm{~L} \mathrm{~min}^{-}$ ${ }^{1}$ to $180 \mathrm{~L} \mathrm{~min}^{-1}$ and up to $245 \mathrm{~L} \mathrm{~min}^{-1}$, respectively. The pressure loops distribution shapes observed in Figure 7, are similar to the observations made by Tsutsumi et al [21], when studying a circulating fluidised bed coal gasifier. They reported a pressure decrease to $0 \mathrm{~Pa}$ in the intersection of the riser and primary cyclone. In addition the larger sand particle size $(0.6 \mathrm{~mm})$ has a significant effect on pressure predictions as shown in Figure 8 below.
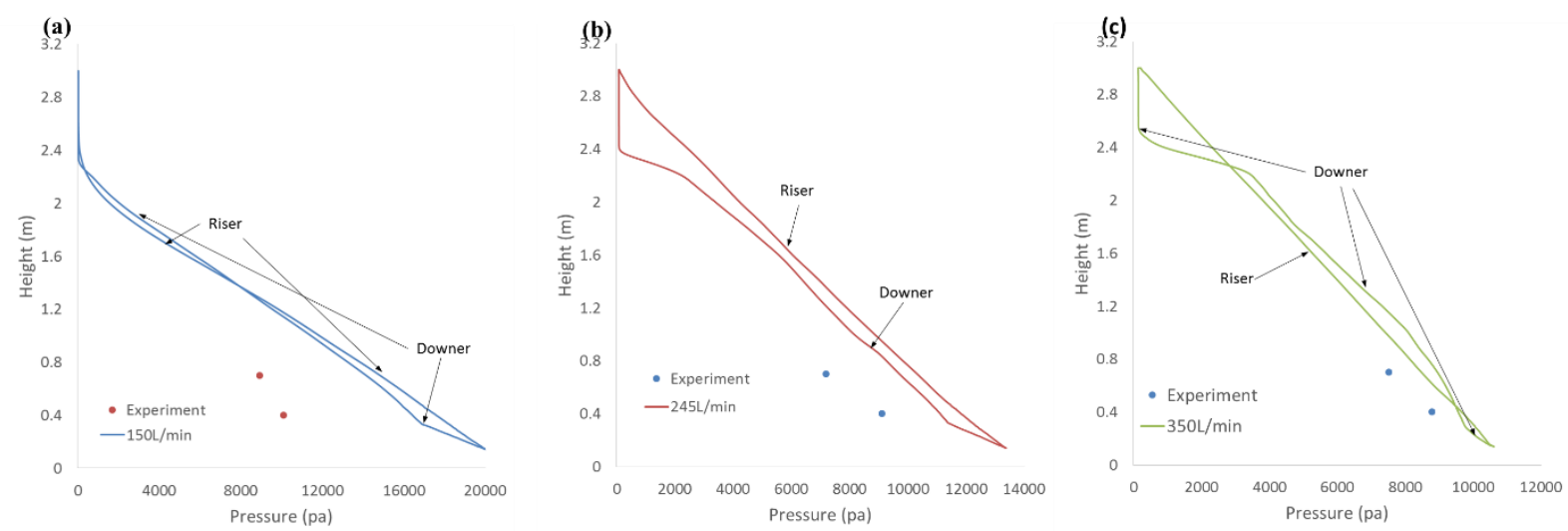

Figure 8. Time-averaged pressure loops around the CFB system operated with sand of $0.6 \mathrm{~mm}$

Figure 8 shows that the pressure difference between the riser and downer becomes insignificant with large $0.6 \mathrm{~mm}$ particles. In Figure 8 is also observed that as the air flow increased from $150 \mathrm{~L} / \mathrm{min}$ (Figure 8a) up to $245 \mathrm{~L} / \mathrm{min}$ (Figure $8 \mathrm{~b}$ ), the pressure intersection disappears, however, the further increase of the air flow rate up to $350 \mathrm{~L} / \mathrm{min}$ (Figure 8c), resulted in this pressure intersection to appear again. From the experiments it was observed that the pressure was reduced as the particle size increase from $0.3 \mathrm{~mm}$ to $0.6 \mathrm{~mm}$, the simulation also showed this trend. However from the simulation average pressures around $2000 \mathrm{~Pa}$ were obtained, whereas from the experiments were around $4000 \mathrm{~Pa}$. This difference can be attributed to the limitations of the CFD model regarding maximum particle size. 
In general it was observed, both experimentally and from the CFD simulations, that the acceleration of particles increases when increasing the gas velocity and decreasing particle size of solids. These observations are in agreement with previous observations in the literature [10, 22, 23].

\subsection{Solids distribution}

The increase in the silica sand particle size $\left(d_{p}\right)$ from $0.3 \mathrm{~mm}$ to $0.6 \mathrm{~mm}$, as well as the variations in the overall bed density, increased the air requirements in order to attain a stable solids recirculation between the riser and the downer, and also to maintain the mass flux $\left(G_{s}\right)$. This observation has been previously reported by Kim et al, they also reported that the increase in the particle size from 78 micros up to 239 micros decreased the solid holdup in the riser and also decreased the pressure drop [24].

To reduce the fluctuation of solids concentration and better present the influence of air flow rate on particulate suspension of air-sand two phase flow under different air flow rate from 100 to $245 \mathrm{~L} / \mathrm{min}$, the time averaged solid concentration distribution of sand at particle size $0.3 \mathrm{~mm}$ along axis line is shown in Figure 9 below. It is the first time that solid holdup loops around a CFB system have been numerically predicted. According to the author's knowledge, this type of holistic predictions have not been reported so far for a CFB system and using CFD. The advantage of showing the spatial distribution of sand (Figure 9), is to provide guidance to evaluate the hydrodynamic performance of CFB under chosen operation conditions and including the material's properties.
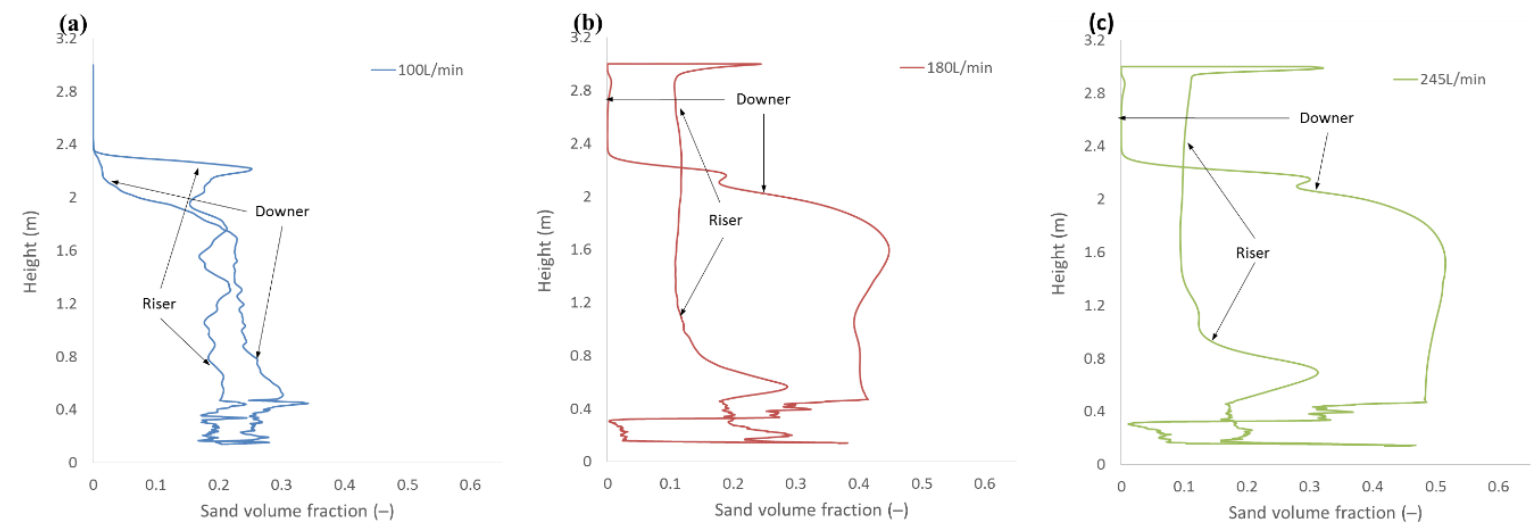

Figure 9. Time-averaged solid holdup loops around the CFB system operated with sand of $0.3 \mathrm{~mm}$

Figure 9a depicts an irregular distribution of solid holdup loop at low air flow rate $100 \mathrm{~L} / \mathrm{min}$, and air velocity of $1.33 \mathrm{~m} / \mathrm{s}$, in consequence the air-sand flow is not fully developed, which is confirmed by contour snapshot of solid concentration distribution in Figure 4 (Section 4.1, Flow pattern). As the air flow rate and air velocity are increased to $180 \mathrm{~L} / \mathrm{min}$ and $2.39 \mathrm{~m} / \mathrm{s}$ respectively (Figure $9 \mathrm{~b}$ ), the volume fraction of sand is almost constant up the riser, which indicates that a fast fluidization regime and a fully developed flow are formed. 
The dilute solid concentration is observed on the top of the downer (Figure 9b, within the cyclone, where a rapid separation of the air-sand occurs. As the air flow rate and air velocity are further increased to $245 \mathrm{~L} / \mathrm{min}$ and $3.25 \mathrm{~m} / \mathrm{s}$ respectively (Figure 9c), the fast circulation rate of sand speeds up the transport of sand up the riser and in the downer side, the solid concentration increases (from 0.4 to 0.5 as shown in Figure $9 \mathrm{~b}$ and $9 \mathrm{c}$ ) owing to the increase of recirculation rate.

The effects of varying the air velocity when using coarse particles $(0.6 \mathrm{~mm})$, is shown in Figure 10 below. It shows larger resistance of coarse sand particles $(0.6 \mathrm{~mm})$ hinder the achievement of good sand circulation, even with large air flow rate and gas velocity.
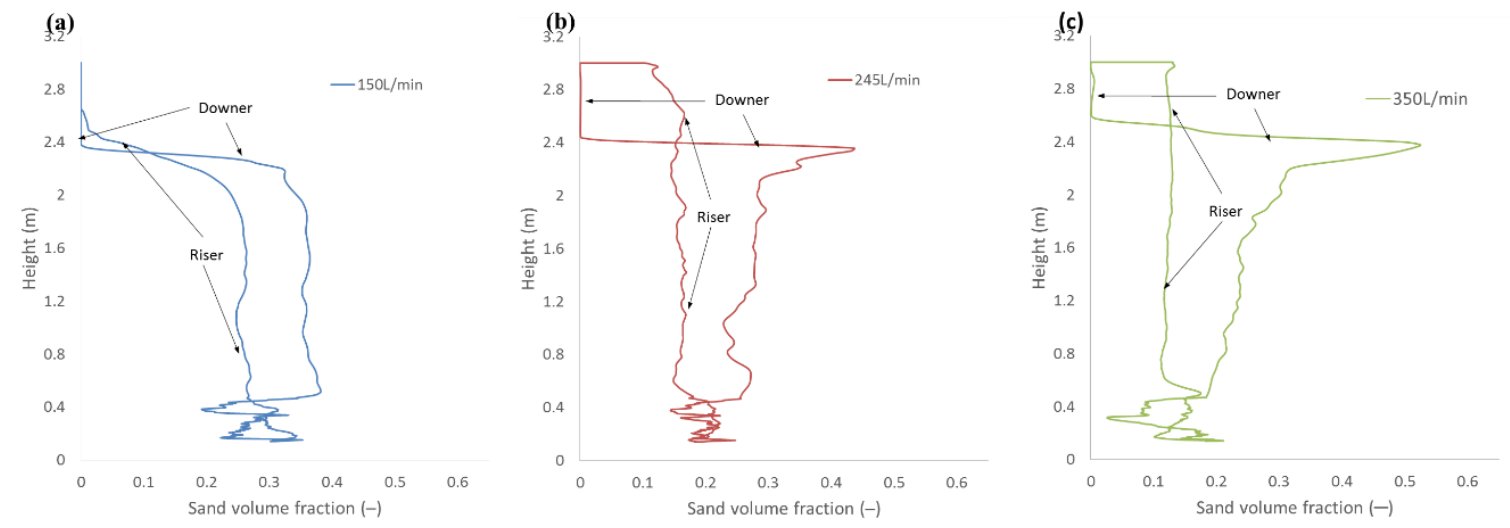

Figure 10. Time-averaged solid holdup loops around the CFB system operated with sand of $0.6 \mathrm{~mm}$

As mentioned earlier in this section, it is the first time that solid holdup loops are shown by the present authors. The ideal spatial distribution of solid holdup within system should behaves as fast fluidisation in the riser with uniform solid distribution, and fast falling down stream of recirculated sand with homogeneous concentration in the downer side [25]. The perfect achievement of good circulation and its corresponding solid holdup distribution can be seen in Figure 9b and Figure 9c, which is operated with fine particles of $0.3 \mathrm{~mm}$. In conclusion, the fine particle size $0.3 \mathrm{~mm}$ is preferred in the further system test and operation. This is because firstly the relatively low air flow rate requirement to achieve a good particle suspension and recirculation, this low air flow rate will be further reflected in cost economic. Secondly, the sand plays important role in heat transfer process for biomass gasification, the use of fine particles intensifies the mixing intensity and heat transfer coefficient, which increases heat transfer efficiency. Finally as sand plays important roles as catalyst in tar cracking, the utilisation of fine particle increases the total surface area, which will reduce tar concentration and promote conversion efficiency of syngas. Thermal tar cracking reactions might also be promoted thanks to more homogeneous temperatures achieved by a greater heat transfer efficiency, thus resulting in a higher quality syngas. 
In general it was noted that the solid holdup loops trend, is similar with the trend of pressure distribution (Figure 5 and Figure 6), as the solid concentration between riser and downer becomes insignificant compared to small particle with $0.3 \mathrm{~mm}$.

\section{CFD simulation of reactive operational condition}

A CFD simulation of reactive operational conditions is conducted to explore the feasibility of current CFB for beech wood gasification. The Eulerian-Eulerian multiphase hydrodynamics model used in section 4 is extended to deliberate the interactions among biomass, sand and gas phases, which includes hydrodynamics, heat transfer and chemical reactions. Biomass and sand phases are treated as interpenetrating continuous phases using KTGF granular model and frictional flow law in ANSYS-Fluent V15. The commercial code solves the transient governing equations of mass, momentum and energy, species transport for gas mixture and multiple solid phases. The reaction kinetic of biomass gasification is not encompassed in the ANSYS-Fluent V15. Consequently, the chemistry scheme is executed in the CFD model using in-house developed UDF in C++ language to fill the technical gap. The chemical composition of beech wood and operational condition for simulation are listed in Table 4. It is CPU costing for running a real process simulation, thus the present simulation of biomass feeding started from a pseudo steady state, which refers the sand assumed to be heated-up at $800 \mathrm{C}$. The wall of CFB are assumed as adiabatic.

Table 4: Beech composition and operational conditions

\begin{tabular}{ll}
\hline Parameter & Value \\
\hline Beech wood & \\
Proximate analysis (wt.\%) & \\
Moisture (wt.\%) & 5.8 \\
Volatile matter (wt.\%) & 77.7 \\
Fixed carbon (wt.\%) & 14.9 \\
Ash content [\%] & 1.6 \\
HHV (kJ/kg) & \\
Ultimate analysis (wt.\%, dry basis) & \\
$\mathrm{C}$ & 46.83 \\
$\mathrm{H}$ & 5.93 \\
$\mathrm{O} *$ & 46.91 \\
$\mathrm{~N}$ & 0.20 \\
$\mathrm{~S}$ & 0.03 \\
$\mathrm{Cl}$ & 0.10 \\
Biomass feeding rate $(\mathrm{kg} / \mathrm{h})$ & 3 \\
Sand as bed materials $(\mathrm{kg})$ & 3 \\
Air feeding rate $(\mathrm{kg} / \mathrm{h})$ & 5.45 \\
ER (equivalence ratio) & 0.34 \\
\hline Obtained by difference &
\end{tabular}




\subsection{Gasification chemistry in CFD model.}

Pyrolysis means primary decomposition of the biomass feedstock which results in char, tar, light gaseous and water vapour. The pyrolysis step is simulated using a global model that describes devolatilization as a single reaction in Eq. 7 [26], [27], [28]. The stoichiometric coefficients $\left(\alpha_{i}\right)$ for beech wood pyrolysis reaction are derived based on the method developed by Boateng and Mtui [26]. These are determined from molar elemental balances of carbon, hydrogen and oxygen in the beech wood $\left(\mathrm{C}_{6} \mathrm{H}_{8.7} \mathrm{O}_{4.5}\right)$ and the corresponding composition of the pyrolysis products of bio-oil $\left(\mathrm{C}_{6} \mathrm{H}_{8.65} \mathrm{O}_{1.34}\right)$ [29], gas and char obtained from a TGA analysis. In this study, we derived the coefficients $\alpha_{1}$ through $\alpha_{7}$ in Eq. 7 for beech wood were $0.894,0.603,1.504,0.021,0.803,0.697$ and 0.126 .

$$
\text { BIOMASS } \rightarrow \alpha_{1} \text { CHAR }+\alpha_{2} \text { BIO.OIL }+\alpha_{3} \mathrm{H}_{2} \mathrm{O}+\alpha_{4} \mathrm{H}_{2}+\alpha_{5} \mathrm{CO}+\alpha_{6} \mathrm{CO}_{2}+\alpha_{7} \mathrm{CH}_{4} \text { (7) }
$$

The rate of the pyrolysis reaction in Eq. 8 is derived for biomass pyrolysis [30].

$r=k \alpha_{s_{2}}\left[C_{v o l}\right]$

where $C_{v o l}$ is the concentration of the volatiles in the biomass and $k$ is the reaction rate constant given by an Arrhenius kinetic format as follow:

$k=A \exp [-E / R T]$

where the pre-exponential factor $A$ and the activation energy $E$ used are $1.22 \times 10^{7} \mathrm{~s}^{-1}$ and $9.967 \times 10^{7} \mathrm{~J} / \mathrm{Kmol}$ respectively [30].

Primary tar refer organic tar mixtures with large molecular weight. Primary tar is formed in absence of oxygen from solid biomass via primary pyrolysis, in a temperature range of 400$700^{\circ} \mathrm{C}$. With continuous exposure to a heated environment, primary tar can endure secondary tar reactions (STR), which alters both mass and composition of the resulting liquid [31]. Secondary pyrolysis is normally considered lumped [32] [33], and the actual composition of the Tar is ignored. Although tar is a complex mixture including up to 100 species, which is difficult to be modelled, Mellin et al. [34] developed a novel CFD model coupled with a 
comprehensive chemistry scheme (134 species and 4169 reactions, in CHEMKIN format) to investigate this complex phenomenon.

Seebauer et al. [35] found a primary tar yield of $52.8 \mathrm{wt} . \%$ (of wood) and an ultimate tar yield at long residence times at high temperatures of $5.79 \mathrm{wt} . \%$ (of wood). So from the primary tar 11 wt.\% was left. Rath et al. [36] examined the reaction kinetics of tar cracking from fast pyrolysis of large beech wood particles. This ultimate yield was considered to be due to a nonreactive tar fraction. In this paper the fraction of non-reactive tar $V^{*}$ from primary tar from beech wood was determined to be $22 \mathrm{wt} . \%$ of primary tar.

After the formation of primary tar vapour from primary pyrolysis, the thermal environment under high temperature drives secondary cracking of tar to inert tar and light molecular-weight gas $\left(\mathrm{CO}, \mathrm{CO}_{2}, \mathrm{H}_{2}\right.$ and $\left.\mathrm{CH}_{4}\right)$. The detail of tar cracking model is explored in the literatures [37], [38], [39].

$$
\text { Tar } \rightarrow \alpha_{1} \text { Tarinert }_{\text {in }}+\alpha_{2} \mathrm{H}_{2}+\alpha_{3} \mathrm{CO}+\alpha_{4} \mathrm{CO}_{2}+\alpha_{5} \mathrm{CH}_{4} \text { (10) }
$$

The cracking rate of tar is given in form of Arrhenius type law, with pre-exponential factor $A$ $=10^{5.14} \mathrm{~s}^{-1}$ and the activation energy $E=9.337 \times 10^{7} \mathrm{~J} / \mathrm{Kmol}[36]$.

$$
-\frac{d V}{d t}=A \times \exp \left(-\frac{E}{R T}\right) \times\left(V_{t}-V^{*}\right)
$$

The produced composition of inert tar and gas mixture from primary tar cracking are derived from the experimental data ([38] and [40]). 22\% mass weight of primary tar are remained as inert tar, meanwhile, $78 \%$ mass weight of primary tar are cracked into $56.33 \% \mathrm{CO}, 8.84 \%$ $\mathrm{CH}_{4}, 11.1 \% \mathrm{CO}_{2}$ and $1.73 \% \mathrm{H}_{2}$.

The gaseous species taken into account in multiphase model are $\mathrm{N}_{2}, \mathrm{O}_{2}, \mathrm{H}_{2}, \mathrm{CH}_{4}, \mathrm{CO}, \mathrm{CO}_{2}$, water vapour and tar vapour. A reaction mechanism capturing the homogeneous reaction in gas phase is given by the first four reactions in Table 5. The modelling of heterogeneous reactions for solid char depends necessarily on the available gas phase species in the surrounding atmosphere. Four heterogeneous reactions of char are given in Table 5. The kinetic parameters and reaction rates for the reactions above are taken from the CFD study of wood gasification done by Gerber et al. [37]. 
Table 5: Homogeneous and heterogeneous reactions [37]

\begin{tabular}{|c|c|}
\hline Equation & Rate expression \\
\hline $2 \mathrm{CO}+\mathrm{O}_{2} \rightarrow 2 \mathrm{CO}_{2}$ & $d[\mathrm{CO}] / d t=-3.98 \times 10^{11} \exp \left(-1.67 \times 10^{11} / \mathrm{RT}\right)[\mathrm{CO}]\left[\mathrm{O}_{2}\right]^{0.25}\left[\mathrm{H}_{2} \mathrm{O}\right]^{0.5}$ \\
\hline $\mathrm{CH}_{4}+\angle \mathrm{U}_{2} \rightarrow \mathrm{CO}_{2}+2 \mathrm{H}_{2} \mathrm{U}$ & $d[C O] / d t=-\left(2780 \exp \left(-1.255 \times 10^{7} / R T\right)[C O]\left[H_{2} \mathrm{O}\right]\right.$ \\
\hline $\mathrm{CO}+\mathrm{H}_{2} \mathrm{O} \rightleftharpoons \mathrm{CO}_{2}+\mathrm{H}_{2}$ & $\left.-1.049 \times 10^{5} \exp \left(-4.557 \times 10^{7} / R T\right)\left[H_{2}\right]\left[\mathrm{CO}_{2}\right]\right)$ \\
\hline $\mathrm{CH}_{4}+\mathrm{H}_{2} \mathrm{O} \rightarrow \mathrm{CO}+3 \mathrm{H}_{2}$ & $d\left[\mathrm{CH}_{4}\right] / d t=-30 \exp \left(-1.247 \times 10^{8} / R T\right)\left[\mathrm{CH}_{4}\right]\left[\mathrm{H}_{2} \mathrm{O}\right]$ \\
\hline $\mathrm{C}+\mathrm{CO}_{2} \rightarrow 2 \mathrm{CO}$ & $d\left[\mathrm{CO}_{2}\right] / d t=-342 \times T \times \exp (-15600 / T)\left[\mathrm{CO}_{2}\right]$ \\
\hline $\mathrm{C}+\mathrm{H}_{2} \mathrm{O} \rightarrow \mathrm{CO}+\mathrm{H}_{2}$ & $d\left[\mathrm{H}_{2} \mathrm{O}\right] / d t=-342 \times T \times \exp (-15600 / T)\left[\mathrm{H}_{2} \mathrm{O}\right]$ \\
\hline $\mathrm{C}+2 \mathrm{H}_{2} \rightarrow \mathrm{CH}_{4}$ & $d\left[H_{2}\right] / d t=-0.342 \times T \times \exp (-15600 / T)\left[H_{2}\right]$ \\
\hline $\mathrm{C}+\mathrm{O}_{2} \rightarrow \mathrm{CO}_{2}$ & $d\left[O_{2}\right] / d t=-\left(1 / K_{k i n}+1 / K_{D i f}\right)^{-1}\left[O_{2}\right]$ \\
\hline Kinetics rate constant & $K_{k i n}=A T_{s}^{n} \exp (E / R T)=1.04 \times 10^{5} \times \mathrm{T} \times \exp (-11200 / T)$ \\
\hline Sherwood number & $S h=2.0+0.552 \operatorname{Re}^{1 / 2} \operatorname{Pr}^{1 / 3}$ \\
\hline Diffusion coefficient & $D_{g s}=8.34 \times 10^{-6} T^{1.75} / P$ \\
\hline Diffusion rate constant & $K_{\text {Dif }}=S h D_{g s} w_{C} /\left(R T_{S} d_{s}\right)$ \\
\hline
\end{tabular}




\subsection{Gas quality from CFD predictions}

Fig. 11 shows the distribution of the gasification gaseous products including condensable gases (water vapour, tar and inert tar) and non-condensable gases $\left(\mathrm{CO}, \mathrm{CO}_{2}, \mathrm{CH}_{4}\right.$ and $\left.\mathrm{H}_{2}\right)$. The contour plot were obtained from steady stage, when all the gaseous components at CFB exit reached the equilibrium of gasification.

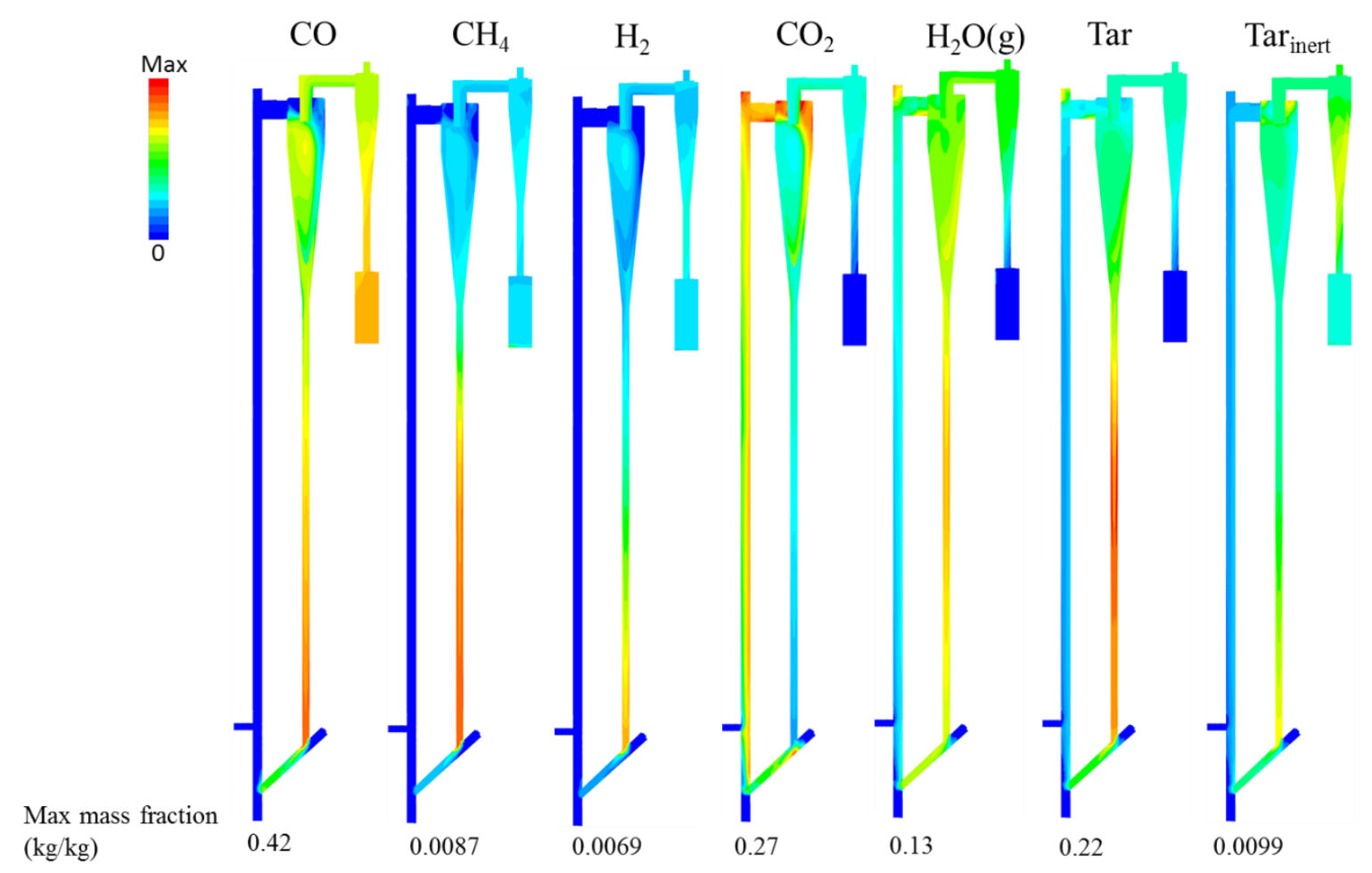

Figure 11. Fuel gas distribution along with CFB domain at steady state

\begin{tabular}{|c|c|}
\hline Species & $\left(\mathrm{m}^{3} / \mathrm{m}^{3}\right) \%$ \\
\hline $\mathrm{CH}_{4}$ & 0.33 \\
\hline $\mathrm{CO}$ & 24.99 \\
\hline $\mathrm{CO}_{2}$ & 6.16 \\
\hline $\mathrm{H}_{2}$ & 1.87 \\
\hline $\mathrm{H}_{2} \mathrm{O}$ & 10.75 \\
\hline $\mathrm{N}_{2}$ & 53.38 \\
\hline $\mathrm{O}_{2}$ & 0.00 \\
\hline Tar & 2.40 \\
\hline $\operatorname{Tar}_{\text {inert }}$ & 0.13 \\
\hline Total & 100.00 \\
\hline
\end{tabular}


Table 7: Fuel gas quality

\begin{tabular}{cc}
\hline Parameter & Value \\
\hline Exit temperature $(\mathrm{C})$ & 724 \\
$\left.{ }^{3} \mathrm{~h}\right)$, wet basis & 24.8 \\
Fuel gas yield $\left(\mathrm{m}^{3} / \mathrm{h}\right)$, dry basis & 22.1 \\
Fuel gas yield $\left(\mathrm{m}^{2}\right.$ composition & $\left.3^{3} / \mathrm{m}^{3}\right) \%$ \\
Dry fuel gas co & 6.9 \\
$\mathrm{CO}_{2}$ & 2.1 \\
$\mathrm{H}_{2}$ & 0.4 \\
$\mathrm{CH}_{4}$ & 59.8 \\
$\mathrm{~N}_{2}$ & 28.0 \\
$\mathrm{CO}^{3}$ & 9.0 \\
Tar $(\mathrm{g} / \mathrm{Nm})^{\text {before purification }}{ }^{3}$ & 3.9 \\
\hline
\end{tabular}

Ruiz et al. [41] comprehensively reviewed the factors to be taken into consideration when selecting the type of gasifier. The fuel gas quality produced from CFB might be: 4.5-13 LHV $\left(\mathrm{MJ} / \mathrm{NM}^{3}\right)$, 4-20 $\operatorname{tar}\left(\mathrm{g} / \mathrm{NM}^{3}\right)$ and high ash and particles in syngas. The quality of fuel gas numerically predicted (Table 6-7) in this study matches the quality range of syngas mentioned in the review [41]. The gas composition is obtained at the tip of the gas exit above secondary cyclone. Furthermore, the results in terms of fuel gas composition, were compared against those reported by Garcia-Ibanez et al, 2004 [42]. They used leached orujillo as feedstock in a $\mathrm{CFB}$ gasifier at $780{ }^{\circ} \mathrm{C}$, with an $\mathrm{ER}=0.41$. They reported a syngas composition of $21.7 \mathrm{vol} . \%$, 5.4 vol.\%, 3 vol.\%, 59.46 vol.\%, 8.6 vol.\% for $\mathrm{CO}_{2}, \mathrm{H}_{2}, \mathrm{CH}_{4}, \mathrm{~N}_{2}$, and $\mathrm{CO}$ respectively. The major differences for $\mathrm{CO}_{2}$ and $\mathrm{CO}$, when compared against the CFD results from our model are attributed to the different reactor configuration as well as to the feedstock composition. However this serves as a very good validation step for the developed model when compared against experimental data.

\subsection{Influence of temperature}

In biomass gasification a reliable heat transfer model is imperative to precisely compute the heat balance within CFB system including reaction heat, external heating (from heaters), input heat from reactant, output heat from products, remaining heat from residues (ash and char), and heat losses (by convection). In order to demonstrate the influence of the thermal properties of gas on the heat transfer, two air-sand heat transfer coefficients were calculated from constant air properties and temperature-depend air properties respectively. The effect of the thermal properties on air heat transfer is shown in the Fig.12 below. 


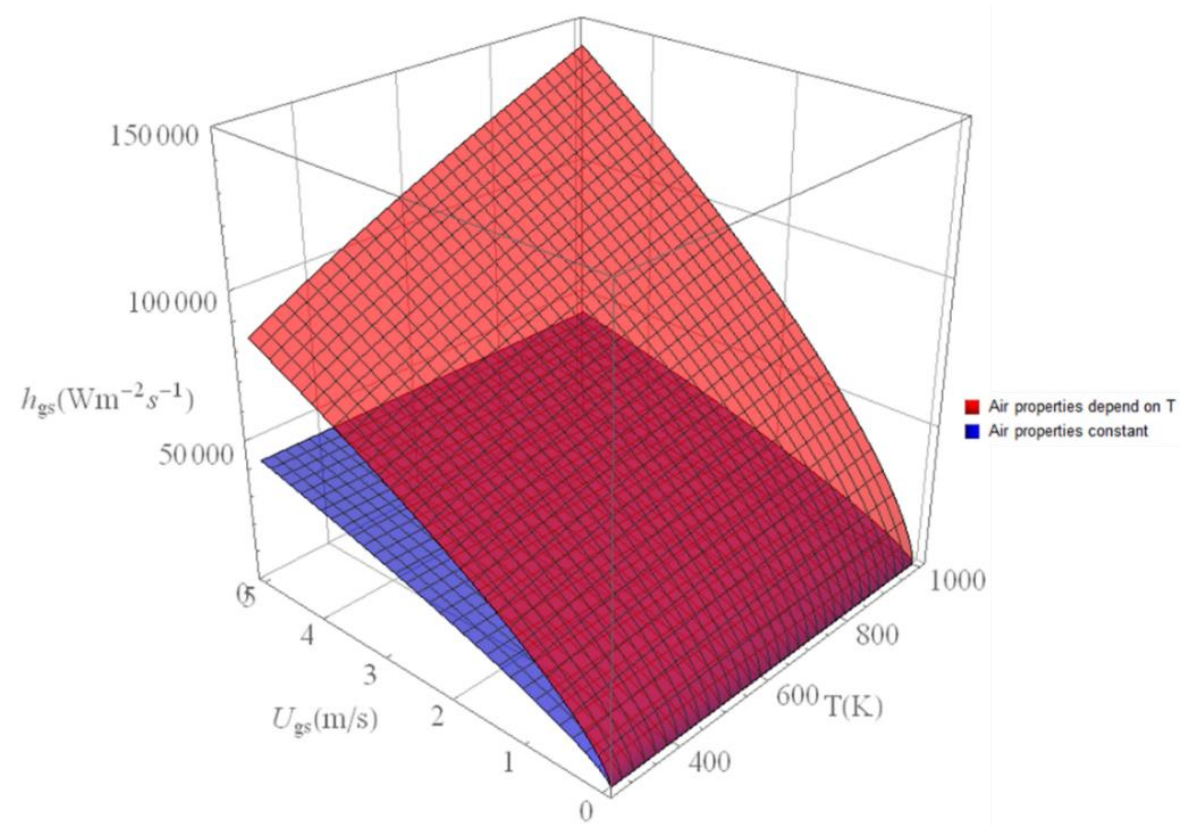

Figure 12. Effects of air properties on the heat transfer coefficient

The air properties used to calculate the heat transfer coefficient are shown as constant values and expressed as function of temperature in Table 8 .

Table 8. Air properties

\begin{tabular}{lll}
\hline \multicolumn{1}{c}{ Property } & Constant & \multicolumn{1}{c}{ Function of temperature, $\boldsymbol{T}(\mathbf{K})[43]$} \\
\hline Density, $\mathrm{kg} / \mathrm{m}^{3}$ & 1.2 & $351 / T$ \\
Viscosity, $\mathrm{Pa} \cdot \mathrm{s}$ & $1.8 \times 10^{-5}$ & $0.42 \times 10^{-6} T^{2 / 3}$ \\
Specific capacity, $\mathrm{J} /(\mathrm{kg} \cdot \mathrm{K})$ & 1006.4 & $\left(0.99+1.22 \times 10^{-4} T-5.68 \times 10^{3} T^{-2}\right) \times 10^{3}$ \\
Thermal conductivity, $\mathrm{W} /(\mathrm{m} \cdot \mathrm{K})$, & 0.024 & $5.66 \times 10^{-5} T+1.1 \times 10^{-2}$ \\
\hline
\end{tabular}

The heat transfer coefficient between air and sand, which is related to the Nusselt number $N u_{s}$, was defined as follows:

$h_{s g}^{\prime}=\frac{\kappa_{g} N u_{s}}{d_{s}}$

Where...

$\kappa_{g}$, is the thermal conductivity of gas phase

$d_{s}$ is the sand particle diameter

The Nusselt number is given by Gunn's correlation, which is applicable to a porosity range of $0.35-1.0$ and Reynolds number of up to $10^{5}$, as follows:

$$
N u_{s}=\left(7-10 \alpha_{g}+5 \alpha_{g}^{2}\right)\left(1+0.7 \operatorname{Re}_{s}^{0.2} \operatorname{Pr}^{1 / 3}\right)+\left(1.33-2.4 \alpha_{g}+1.2 \alpha_{g}^{2}\right) \operatorname{Re}_{s}^{0.7} \operatorname{Pr}^{1 / 3}
$$

As shown in Figure 12 the effect of air properties on the heat transfer coefficient is significant. From Figure 12 it is observed that $200 \%$ higher heat transfer coefficient can be obtained by the temperature- 
dependent air properties, when compared against constant air properties under high temperature and high air-sand slip velocity. We used constant gas properties in the CFD model in this study, however, we recommend the utilisation of temperature-dependent gas properties in the future study.

\section{Conclusions}

The hydrodynamics performance and thermal conversion feasibility of a circulating fluidised bed system (CFB) was investigated both theoretically and experimentally. The following conclusions have been achieved:

1. The flow pattern for Geldart B particles of two different sizes of 0.3 and $0.6 \mathrm{~mm}$, was depicted using a CFD model. The increase in the air velocity promotes the transition from bubbling to turbulent and finally fast fluidization regimes. This was verified using the CFD model developed. By using fine particles a fast fluidization regime was attained using lower air velocities, due to the lower transport velocity and lower resistance force of this particles.

2. The pressure at different points up the riser decreases as the height of the riser increases. Similar with the trend of pressure distribution, the concentration of coarse sand particles $(0.6 \mathrm{~mm})$ between the riser and downer becomes insignificant compared to small particles of $0.3 \mathrm{~mm}$.

3. The static pressure of sand-air mixture decreases when they flow up the riser, and increases when sand is separated from air through the primary cyclone and falls into the downer pipe.

4. The heat transfer coefficient calculated from the air properties depends on temperature and it is higher than the heat transfer coefficient obtained using constant air properties. This, indicates that the parameter setting from the model is important in CFD modelling and predictions.

5. Further studies including heat transfer modelling and experimental in terms of pressure and solid recirculation profiles are still required.

6. The ideal spatial distribution of solid holdup within system should behave as fast fluidisation in the riser with uniform solid distribution, and fast falling stream of recirculated sand with homogeneous concentration in the downer side.

7. Fine solid with particle size of $0.3 \mathrm{~mm}$ is preferred for this system because of the relatively low air flow requirements to achieve a good particle suspension and recirculation, furthermore low air flow rate means lower cost. Secondly, the sand plays an important role in heat transfer process for biomass gasification, fine particles intensify mixing intensity and heat transfer coefficients, which increases heat transfer efficiency. Finally as sand plays an important role for thermal tar cracking, the utilisation of fine particles means an increase in the total surface area, which might reduce tar concentration and promote a higher conversion efficiency of syngas.

8. The fuel gas quality predicted from CFD simulation is: $3.9 \mathrm{LHV}\left(\mathrm{MJ} / \mathrm{Nm}^{3}\right), 9 \operatorname{tar}\left(\mathrm{g} / \mathrm{Nm}^{3}\right)$, which is reasonably consistent with the literature. 


\section{Acknowledgments}

The authors thank to The Engineering and Physical Sciences Research Council (EPSRC) for the project research grant EP/M01343X/1, part of the SUPERGEN Bioenergy Challenge, UK. 


\section{References}

[1] A.V. Bridgwater, Renewable fuels and chemicals by thermal processing of biomass, Chem Eng J 91 (2003) 87-102.

[2] B. Chutichai, Y. Patcharavorachot, S. Assabumrungrat, A. Arpornwichanop, Parametric analysis of a circulating fluidized bed biomass gasifier for hydrogen production, Energy 82 (2015) 406-413.

[3] A. Gomez-Barea, B. Leckner, Gasification of Biomass in Fluidised Bed: Review of Modelling, in: G. Yue, H. Zhang, C. Zhao, Z. Luo (Eds.) Proceedings of the 20th International Conference on Fluidized Bed Combustion, Springer Berlin Heidelberg2010, pp. 13-26.

[4] W. Zhang, H. Liu, I. Ul Hai, Y. Neubauer, P. Schröder, H. Oldenburg, A. Seilkopf, A. Kölling, Gas cleaning strategies for biomass gasification product gas, International Journal of Low-Carbon Technologies 7 (2012) 69-74.

[5] W. Jianzhi, X. Binyang, L. Zhenfang, Z. Xiguang, Performance analysis of a biomass circulating fluidized bed gasifier, Biomass \& Bioenergy 3 (1992) 105-110.

[6] X.T. Li, J.R. Grace, C.J. Lim, A.P. Watkinson, H.P. Chen, J.R. Kim, Biomass gasification in a circulating fluidized bed, Biomass and Bioenergy 26 (2004) 171-193.

[7] M. Siedlecki, W. de Jong, Biomass gasification as the first hot step in clean syngas production process - gas quality optimization and primary tar reduction measures in a $100 \mathrm{~kW}$ thermal input steamoxygen blown CFB gasifier, Biomass \& Bioenergy 35 (2011) S40-S62.

[8] A. van der Drift, J. van Doorn, J.W. Vermeulen, Ten residual biomass for circulating fluidized-bed gasification, Biomass \& Bioenergy 20 (2000) 45-56.

[9] J.-g. Zhu, Y. Yao, Q.-g. Lu, M. Gao, Z.-q. Ouyang, Experimental investigation of gasification and incineration characteristics of dried sewage sludge in a circulating fluidized bed, Fuel 150 (2015) 441447.

[10] P. Wang, X. Yao, H. Yang, M. Zhang, Impact of particle properties on gas solid flow in the whole circulating fluidized bed system, Powder Technology 267 (2014) 193-200.

[11] X. Yu, Y. Makkawi, R. Ocone, M. Huard, C. Briens, F. Berruti, A CFD study of biomass pyrolysis in a downer reactor equipped with a novel gas-solid separator - I: Hydrodynamic performance, Fuel Process Technol 126 (2014) 366-382.

[12] X. Yu, M. Hassan, R. Ocone, Y. Makkawi, A CFD study of biomass pyrolysis in a downer reactor equipped with a novel gas-solid separator-II thermochemical performance and products, Fuel Process Technol 133 (2015) 51-63.

[13] J. Ding, D. Gidaspow, A Bubbling Fluidization Model Using Kinetic-Theory of Granular Flow, Aiche J 36 (1990) 523-538.

[14] D.G. Schaeffer, Instability in the Evolution-Equations Describing Incompressible Antigranulocytes Flow, J Differ Equations 66 (1987) 19-50.

[15] B. Launder, B.D. Spalding, Lectures in Mathematical Models of Turbulence, Academic Press Inc, London, 1972.

[16] D. Gidaspow, Bezburuah, R. , Ding, J. , Hydrodynamics of Circulating Fluidized Beds, Kinetic Theory Approach. , In Fluidization VII, Proceedings of the 7th Engineering Foundation Conference on Fluidization (1992) 75-82.

[17] R.W. Syamlal. M. , O'Brien.T. J., MFIX Documentation: Theory Guide. , Technical Report DOE/METC-94/1004 (DE9400087) (1993).

[18] C.K.K. Lun, S.B. Savage, D.J. Jeffrey, N. Chepurniy, Kinetic Theories for Granular Flow Inelastic Particles in Couette-Flow and Slightly Inelastic Particles in a General Flowfield, J Fluid Mech 140 (1984) 223-256.

[19] M. Syamlal, T.J. O'Brien, Computer Simulation of Bubbles in a Fluidized Bed AIChE Symp. Series. 85 (1989) 22-31.

[20] P.C. Johnson, R. Jackson, Frictional-collisional constitutive relations for granular materials, with application to plane shearing, J Fluid Mech 176 (1987) 67-93.

[21] A. Tsutsumi, G. Guan, C. Fushimi, M. Ikeda, Y. Nakamura, T. Suda, M. Ishizuka, H. Hatano, S. Matsuda, Y. Suzuki, Flow behaviors in a high solid flux circulating fluidized bed composed of a riser, a downer and a bubbling fluidized bed, in: D.S. Kim, Y. Kang, K.J. Lee, C.Y. Seo (Eds.) The 13th 
International Conference on Fluidization: New Paradigm in Fluidization Engineering, ECI Symposium Series, Hotel Hyundai, Gyeong-ju, Korea, 2010.

[22] S. Ouyang, O.E. Potter, Consistency of Circulating Fluidized-Bed Experimental-Data, Ind Eng Chem Res 32 (1993) 1041-1045.

[23] E.R. Monazam, L.J. Shadle, Analysis of the Acceleration Region in a Circulating Fluidized Bed Riser Operating above Fast Fluidization Velocities, Ind Eng Chem Res 47 (2008) 8423-8429.

[24] S.W. Kim, S.D. Kim, Effects of particle properties on solids recycle in loop-seal of a circulating fluidized bed, Powder Technology 124 (2002) 76-84.

[25] J.X. Zhu, Z.Q. Yu, Y. Jin, J.R. Grace, A. Issangya, Cocurrent downflow circulating fluidized bed (downer) reactors - A state of the art review, The Canadian Journal of Chemical Engineering 73 (1995) 662-677.

[26] A. Boateng, P. Mtui, CFD modeling of space-time evolution of fast pyrolysis products in a benchscale fluidized-bed reactor, Applied Thermal Engineering 33 (2012) 190-198.

[27] X. Yu, M. Hassan, R. Ocone, Y. Makkawi, A CFD study of biomass pyrolysis in a downer reactor equipped with a novel gas-solid separator-II thermochemical performance and products, Fuel Processing Technology 133 (2015) 51-63.

[28] M. Bashir, X. Yu, M. Hassan, Y. Makkawi, Modeling and Performance Analysis of Biomass Fast Pyrolysis in a Solar-Thermal Reactor, ACS Sustainable Chemistry \& Engineering 5 (2017) 3795-3807.

[29] E. Schröder, Experiments on the pyrolysis of large beechwood particles in fixed beds, Journal of Analytical and Applied Pyrolysis 71 (2004) 669-694.

[30] C.D. Blasi, C. Branca, Global degradation kinetics of wood and agricultural residues in air, The Canadian Journal of Chemical Engineering 77 (1999) 555-561.

[31] P. Morf, P. Hasler, T. Nussbaumer, Mechanisms and kinetics of homogeneous secondary reactions of tar from continuous pyrolysis of wood chips, Fuel 81 (2002) 843-853.

[32] J.C. Wurzenberger, S. Wallner, H. Raupenstrauch, J.G. Khinast, Thermal conversion of biomass: Comprehensive reactor and particle modeling, AIChE Journal 48 (2002) 2398-2411.

[33] M.L. Boroson, J.B. Howard, J.P. Longwell, W.A. Peters, Heterogeneous cracking of wood pyrolysis tars over fresh wood char surfaces, Energy \& Fuels 3 (1989) 735-740.

[34] P. Mellin, X. Yu, W. Yang, W. Blasiak, Influence of Reaction Atmosphere (H2O, N2, H2, CO2, CO) on Fluidized-Bed Fast Pyrolysis of Biomass Using Detailed Tar Vapor Chemistry in Computational Fluid Dynamics, Industrial \& Engineering Chemistry Research 54 (2015) 8344-8355.

[35] V. Seebauer, J. Petek, G. Staudinger, Effects of particle size, heating rate and pressure on measurement of pyrolysis kinetics by thermogravimetric analysis, Fuel 76 (1997) 1277-1282.

[36] J. Rath, G. Steiner, M.G. Wolfinger, G. Staudinger, Tar cracking from fast pyrolysis of large beech wood particles, Journal of Analytical and Applied Pyrolysis 62 (2002) 83-92.

[37] S. Gerber, F. Behrendt, M. Oevermann, An Eulerian modeling approach of wood gasification in a bubbling fluidized bed reactor using char as bed material, Fuel 89 (2010) 2903-2917.

[38] J. Rath, G. Staudinger, Cracking reactions of tar from pyrolysis of spruce wood, Fuel 80 (2001) 1379-1389.

[39] M.L. Boroson, J.B. Howard, J.P. Longwell, W.A. Peters, Product yields and kinetics from the vapor phase cracking of wood pyrolysis tars, AIChE Journal 35 (1989) 120-128.

[40] V. Seebauer, Experimentelle untersuchungen zur pyrolyse von kohle und holz, na1999.

[41] J.A. Ruiz, M.C. Juárez, M.P. Morales, P. Muñoz, M.A. Mendívil, Biomass gasification for electricity generation: Review of current technology barriers, Renewable and Sustainable Energy Reviews 18 (2013) 174-183.

[42] P. Garcia-Ibanez, A. Cabanillas, J.M. Sanchez, Gasification of leached orujillo (olive oil waste) in a pilot plant circulating fluidised bed reactor. Preliminary results, Biomass \& Bioenergy 27 (2004) 183194.

[43] G. Flamant, J.D. Lu, B. Variot, Towards a generalized model for vertical walls to gas - solid fluidized beds heat transfer-II. Radiative transfer and temperature effects, Chemical Engineering Science 48 (1993) 2493-2503. 